\title{
Prerequisites of creation of the general branch informational system in construction
}

\author{
Irina Karakozova ${ }^{1, *}$ \\ ${ }^{1}$ Moscow State University of Civil Engineering, 129337 Yaroslavskoe shosse 26, Moscow, Russia
}

\begin{abstract}
The article is dedicated to the problem of the absence of any theoretical justification of the process of the creation of the general information space, which would make the effective use of the main types of resources possible during the processes management at all the stages of life cycle in construction. The problems of classification and the problem creation of the system of coding of the material resources considering their main properties and characteristics, as well as the need of creation of any requirements management unit as a part of the information system are separately considered.
\end{abstract}

\section{Introduction}

The relevance of the matter is determined by the need of the theoretical justification and the subsequent formation of any tools for their use within the creation of the general common information space for the purpose of reduction of terms, decrease in expenses and minimization of risks during all the life cycle of projects in construction. On the one hand there is an intensive updating and development of the construction branch and in this regard there is the urgent need to have an information systems allowing to make decisions in due time, qualitatively, openly and with all the responsibility. On the other hand the organizations in the construction branch are not fully ready to adopt such open format of communication, demanding considerable time and financial expenses. In this regard there is the need of justification of the creation of a uniform information space for the purpose of receiving and transfer of data at all the stages of the life cycle of a construction project from the conception of the idea of the construction and up to its elimination.

\section{Prerequisites of creation of the general branch informational system in construction}

It is possible to refer to relevance, unambiguity, orderliness and automation to the principles of development of various systems of classification and coding of various elements in construction. The developed systems are to reflect the existing condition of the market of modern resources, works and projects in construction and to provide

* Corresponding author: i.kar@inbox.ru 
unambiguous perception of data during their description. As information technologies are widely used in construction now, the qualifiers being created and systems of coding have to represent the organizational structure of the interconnected elements, allowing obtaining information about the set element consistently for the purpose of the automated processing of the obtained information and as well for the search of the optimal solution of the task.

Nowadays various qualifiers of projects, works, structures, resources are used in construction. For example, the set of projects and complexes is presented in the All-Russian qualifier of fixed assets OKONF, which is acting since January 01, 1996. The types of works which are carried out in construction are listed in the All-Russian qualifier of types of economic activity. However the expanded list of types of the works performed in construction can be seen in the operating budget regulatory bases where budget costs of the performance of works are formed on the basis of element budget norms and single quotations. Classification of material resources is given in the All-Russian qualifier of production OKP (OK 005-93) which will be acting till January 01, 2017. However it will be replaced by the All-Russian qualifier of production according to the types of economic activity OK 034-2014 (KPES 2008), (Rosstandart) accepted and put into operation by the Order of Federal Agency for Technical Regulation and Metrology of January 31, 2014 No. 14-st. It is possible to name the following main shortcomings of the listed qualifiers:

- Excessive division into the making elements of separate groups or, on the contrary, their huge integration;

- Inexact assignment of the name to the structural units of classification that causes their double treatment;

- Orientation of the existing qualifiers to a certain circle of consumers or separate range of application (such as trade, taxation, etc.).

Now work on the creation of the state information system "Pricing in Construction" aimed at the solution of such tasks as the increase of reliability and transparency of the determination of cost of construction at all the stages of the investment-and-construction project, the improvement of competitive climate in the market of construction materials and the increase in the stability of the market of contract services [1] is being carried out at the moment. The functional subsystem of the formation of the qualifier and management of the catalog of construction resources which will store the information about the resources, used in construction, their actual prices, demands in the design-and-budget documents, etc. will be a part of this system.

This article presents the idea of the creation of the uniform concept of formation of the branch system of classification and codification of information which application due to timeliness, reliability and informational content will increase efficiency of the use of the resources necessary during planning, organization, management and control of works on the project in construction for the purpose of reduction of terms, expenses and risks. Works on the creation of such system must include:

- development of branch system of qualifiers for the purpose of creation of a unified information system which will be used during the information modeling of processes at all the stages of life cycle of a project;

- the direct development of all the qualifiers as a part of a unified information system for the use during the developing, justification and decision-making;

- ensuring the harmonization of the created branch system of classification and coding of information with the operating Russian and international qualifiers.

Databases including, various qualifiers, for example, qualifiers of objects, constructive decisions, works, resources (financial, material, labour, technical, the equipment, etc.), projects, participants (contractors), contracts (contracts), standards, expenses, budgets, risks, requirements, standard and legal documents, technical documents, etc. have to be the basis for the branch information system. Thus, the system being created will play a leading 
role in the accumulation of information, and also in its use during the development and optimization of the design decision as well as in control over its realization.

Creation of a full and reliable classification of material resources seems to be one of the labour-intensive processes in the offered system. First off all it is connected with the fact that it is necessary to consider all the properties and characteristics of resources which have to be united and identified within technologically uniform groups according to practice of their use in the investment-and-construction activity. Identification is meant to be an assignment to projects objects of the group code abbreviated names, their identification and definition of the place (identification) in the created classification system of material resources. At the same time the dictionary fund of the specified nomenclature of resources is based on the reflection of the main consumer properties of production as subjects of labour in the construction production.

The material resources used during the construction, reconstruction, repair of buildings and structures can be classified according to their appointment and origin, taking into account the main properties and characteristics. In this case the material resources will include materials, products, semi-finished products and structures used during construction works. Classification of material resources will include the following groups of resources formed originally on the basis of their appointment:

- construction materials for roadworks, foundations of buildings and structures;

- structural construction materials and products as a part of the bearing and protecting structures;

- functional construction materials for covering of structures;

- materials, products and equipment for technical systems;

- materials, products and equipment for wire systems;

- materials and products for improvement and green construction;

- materials, products and equipment of special and other purposes.

The structure of properties and parameters of the material resources used in classification have to include physical, mechanical, technological, chemical, operational, sanitary and hygienic and esthetic properties of material resources, and also their mass-anddimensional characteristics. As a result when coding a material resource all the information about it can be recorded, from the application and origin and up to the key parameters influencing on the choice of resources according to the established production and engineering requirements of the design decision.

We will refer the set of the construction machines, mechanisms, equipment and tools participating in the process of creation of construction products as well as in the performance of different types of works to the technical resources used in construction.

The groups of technical resources created according to their appointment and entering classification of resources consist from:

- machines, mechanisms and equipment for preparatory works and works on gardening of the territory;

- machines and the equipment used for earthwork;

- machines and the equipment used for pile works;

- machines and the equipment used for concrete works;

- machines and the equipment used for road-building works;

- load-lifting machines, mechanisms and equipment for construction (repair-andconstruction) works;

- machines, mechanisms and equipment for transportation of freights and loading and unloading works;

- machines, mechanisms and equipment for finishing works;

- machines, mechanisms and equipment for special works;

- machines, mechanisms and equipment for auxiliary works; 
- mechanized tools.

Such parameters as capacity, productivity, loading capacity, useful height, synchronous frequency of fluctuations, capacity, etc. belong to the properties of technical resources acting as the for their classification.

Standard-and-technical and other documents validating the set parameters have to act as the basis for the creation of classification. Such documents can include, for example, state standards, industry standards, specifications, standards of large organizations (being customers of the specified products), etc.

When developing the classification the hierarchical method of classification, which characteristics give the possibility of the use of unlimited number of signs of classification and hierarchy of signs of the classification, is accepted. Namely, in this case the group formed according to one sign is divided into a set of classification groups according to a subordinate (subordinate) sign.

The created qualifier of material resources as a part of branch information system will allow to create the database, which structure besides the list of properties and technical characteristics of resources can include the following information:

- graphic materials of the resources used or intended to be used;

- factual information (operational data for providing operating conditions, energy consumption parameters, number and qualification of personnel, etc.);

- structure of suppliers and producers of material resources with a summary about them (location, requisites, the nomenclature of the delivered resources, the certificate of activity, etc.);

- price indicators of resources based on price lists and catalogs of suppliers and producers;

- statistical information on structure of resources, technologies, etc. depending on appointment and the size of object, a stage of its life cycle.

However the complexity of the creation of such a system is that in during the use it will demand continuous replenishment by new information and the updating which is already available as a part of the database.

It is also necessary to note the need of the use of this information system when developing resource-and-technological models in construction for the purpose of formation of budget indicators of various level of integration. For example, for the creation of a cost index the unified set of the labour, material and technical resources necessary for performance of separate types or complexes of works, creations of constructive elements or the building (structure) in general is formed. In this case the total cost of separate types of works as well as the cost of object in general depends on the structure of resources, their characteristics and price indicators. Completeness and reliability of the formed indicator can be obtained on the basis of the offered information system allowing to consider the diversity of decisions, to choose the most optimum and, if necessary to make changes in due time.

The unit of requirements management, representing also the hierarchical system where each branch has to reflect requirements to the designated group has to hold a specific place in information system. For example, the requirements to the structure can include the following groups [2]:

- requirements of government bodies (environmental protection, architectural expressiveness);

- requirements of the user during the operation of the structure depending on its appointment (durability, maintainability, productivity, etc.);

- requirements of the customer (economic efficiency, payback);

- requirements of supervision (observance of the existing normative documents); 
- requirements of the contractor (technological effectiveness, labour protection, quality of resources, works, etc.).

Requirements to the project documents can include such groups as:

- requirements of government bodies (observance of acts and the existing standard and methodical documents);

- requirements of the customer (validity of the made architectural, technological and technical decisions, optimization of cost);

- requirements of supervision (observance of the existing standard-and-methodical documents, requirements to structure of documents, the requirement to completing of documents, validity of the used resources, etc.)

- requirements of the contractor (confirmation of the made decisions in the field of resource management, requirements to the structure of reporting documents, etc.).

The process of the formation and the use of such block consists of collecting, processing, analysis, formulation and approval of requirements with the obligatory subsequent tracking of their execution during design, construction, operation and elimination of the project. As for the customer he or she initially has to create the list of requirements for the purpose of the subsequent their transfer to the design and contract organizations and control for from performance. Owing to certain circumstances, such as discrepancy of the resource offered to application to the requirements of the set parameters, the requirements, established earlier can be modified or changed and that surely has to be confirmed by proving materials.

Thus, the information system has to comprise a large number of data which will get the necessary sense only in the certain conditions made, for example, by the design decision.

\section{Conclusion}

By now in the Russian Federation the certain experience in the field of the development of various systems of classification used in construction for the justification of the forthcoming expenses during the planning of production, design of structures, management of expenses has been saved up. Creation of a common information space will promote quick and flexible response to the happening changes that will allow to make managerial decisions taking into account all the influencing factors of the external and internal environment of the structure. Classification and coding of information used in construction are the most important prerequisites of the modern approach to the project management, as well as to logistics, development of resource and technological models, drawing up budget documents, information support of the life cycle. However despite a lot of work which is carried out in this direction, the search of the unified approach satisfying all the participants of construction is still proceeding.

\section{References}

1. Information on: www.nopriz.ru/upload/iblock/aa6/text_postanovlenie_pravitelstva_npa_39886.pdf

2. E.A. Gusakova, A.S. Pavlov, Principles of organization and management in construction. In 2 parts, part 1 (Urayt, Moscow, 2016)

3. M. Jocovic, B. Melovic, N. Vatin, V. Murgul, Applied Mechanics and Materials, 678, 644-647 (2014)

4. G. Radovic, V. Murgul, N. Vatin, Applied Mechanics and Materials, 641-642, 634$638(2014)$ 
5. J. Ćetković, S. Rutešić, M. Zarković, M. Knežević, , N.Vatin, Procedia Engineering, 117 (1), 780-790 (2015)

6. S. Rutešić, J. Ćetković, M. Žarcković, M. Knežević, N. Vatin, Procedia Engineering, 117 (1), 905-915 (2015)

7. S. Rutešić, J. Ćetković, M. Knežević, M. Žarcković, N. Vatin, Procedia Engineering, 117(1), 642-650 (2015)

8. J. Cetkovic, S. Rutesic, T. Hanak, M. Knezevic, B. Melovic, Technics Technologies Education Management, 7(1), 285-293 (2012)

9. V.V Okrepilov, M.V. Leonidovich, Asian Social Science, 11(7), 312-325 (2015)

10. V.V Okrepilov, V.L. Makarov, A.R. Bakhtizin, S.N Kuzmina, Economy of Region, 2, 301-313 (2015)

11. V.L. Kvint, V.V Okrepilov, Herald of the Russian Academy of Sciences, 84(3), 188200 (2014)

12. G. Radovic, V. Murgul, N. Vatin, E. Aronova, Applied Mechanics and Materials, 627, 357-364 (2014) 